\title{
TRATAMENTO DE EFLUENTES ÁCIDOS PARA A REMOÇÃO DO MANGANÊS E DE METAIS PESADOS ASSOCIADOS AOS EFLUENTES DA MINERAÇÃO DE CARVÃO POR MEIO DOS PROCESSOS DE FLOCULAÇÃO E FLOTAÇÃO POR AR DISSOLVIDO TREATMENT OF ACID EFFLUENTS FOR THE REMOVAL OF MANGANESE AND HEAVY METALS ASSOCIATED WITH EFFLUENTS FROM THE COAL MINING THROUGH THE PROCESSES OF FLOCULATION AND FLOTATION BY DISSOLVED AIR
}

\section{Samira Becker Volpato $(1)$}

Doutoranda em Ciências

Ambientais na Universidade do Extremo Sul Catarinense (UNESC) Criciúma (SC), Brasil.

\section{Antuni Crescencio (1)}

Engenheiro ambiental na UNESCCriciúma (SC), Brasil.

\section{Carlyle Torres Bezerra de Menezes (1)}

Professor doutor em Engenharia Mineral na Universidade do Extremo Sul Catarinense (UNESC) Criciúma (SC), Brasil.

\section{Andre Escobar (1)}

Engenheiro químico na Carbonífera MetropolitanaCriciúma (SC), Brasil.

\section{Endereço para correspondência:}

Carlyle Torres Bezerra de Menezes Rua Antônio Sartor, 439 - Mina do Mato - CEP: 88810-470Criciúma (SC), Brasil E-mail: cbm@unesc.net

Recebido em: 02/12/2019

Aceito em: 10/06/2020

\section{RESUMO}

Este estudo foi desenvolvido com o objetivo de avaliar os processos de tratamento de efluentes provenientes da mineração de carvão mineral, bem como sua eficiência na remoção de manganês e de outros metais pesados. Os procedimentos consistiram na aplicação dos métodos de tratamento de efluentes de mineração por meio do processo de neutralização, seguido de floculação e sedimentação (NFS) e flotação por ar dissolvido (FAD) em escala de bancada. O ensaio via NFS apresentou eficiência de $99,58 \%$ na remoção do manganês dissolvido no efluente, com a elevação de $\mathrm{pH}$ até 9,95. Para os ensaios por FAD, a eficiência média da remoção de manganês foi de $97,12 \%$ e o pH 9,4. Para os outros metais, a NFS apresentou remoção de $99,79 \%$ para o alumínio total, $99,32 \%$ para o zinco e $97,79 \%$ para o ferro solúvel, enquanto a FAD apresentou remoção média de $96,33 \%$ para o alumínio total, 97,02\% para o zinco e $97,26 \%$ para o ferro solúvel. Todos os ensaios se enquadraram nos limites estabelecidos pela legislação ambiental no que diz respeito à concentração em metais tóxicos. Isso comprova que o processo de tratamento do efluente proveniente de uma empresa carbonífera em estudo apresentou eficiência para a remoção dos metais analisados, sobretudo ferro, zinco e manganês. Resta a necessidade de ajustes em futuros trabalhos de pesquisa a adequação do manganês a valores de $\mathrm{pH}$ abaixo de 9 . Constatou-se ainda que, além da NFS, a técnica de tratamento por FAD constitui uma alternativa para o tratamento de efluentes ácidos de mina, corroborando trabalhos anteriores e justificando a possível reintrodução futura nos sistemas de tratamento da drenagem ácida de mina na região.

Palavras-chave: drenagem ácida de mina; contaminantes ambientais; metais tóxicos.

\section{ABSTRACT}

This study was developed with the objective of evaluating the effluent treatment processes from coal mining, as well as the efficiency in removing manganese and other heavy metals. The procedures consisted of applying mining wastewater treatment methods through the neutralization processes, followed by Flocculation and Sedimentation (NFS) and Dissolved Air Flotation (FAD) on a bench scale. The test via NFS showed an efficiency of $99.58 \%$ in the removal of the manganese dissolved in the effluent, with an increase in $\mathrm{pH}$ up to 9.95. For the FAD tests, the average manganese removal efficiency was $97.12 \%$ and with $\mathrm{pH}$ 9.4. For other metals, NFS showed $99.79 \%$ removal for Total Aluminum, $99.32 \%$ for Zinc and $97.79 \%$ for Soluble Iron, while FAD had an average removal of $96.33 \%$ for Total Aluminum, $97.02 \%$ for Zinc, and $97.26 \%$ for Soluble Iron. All tests fell within the limits established by 
environmental legislation with respect to the concentration in toxic metals, this proves that the process of treating the effluent from a coal company under study showed an efficiency for the removal of the analyzed metals, especially iron, zinc, and manganese. There remained the need for adjustments in future research work to adapt manganese to $\mathrm{pH}$ values below 9.0. It was also found that, in addition to the NFS, the FAD treatment technique constitutes an alternative for the treatment of acid mine effluents, corroborating with previous works and justifying a possible future reintroduction in the systems of treatment of acid mine drainage in the region.

Keywords: mine acid drainage; environmental contaminants; toxic metals.

\section{INTRODUÇÃO}

A atividade de lavra e beneficiamento de carvão mineral na região sul do estado de Santa Catarina teve início no fim do século XIX, mas somente em meados da década de 1940 obteve grande impulso, quando começou a ser implantado o parque siderúrgico nacional (MENEZES et al., 2004). Porém, aliada ao progresso da região sul, a mineração de carvão trouxe consigo severos danos ambientais, comprometendo a qualidade do ar atmosférico, dos solos e dos recursos hídricos locais.

Um dos principais impactos da atividade mineira é a poluição hídrica causada pela drenagem ácida de mina (DAM). Os problemas ambientais estão relacionados com o pH geralmente abaixo de 3 e a diversidade de metais dissolvidos, como ferro, alumínio, manganês e traços de chumbo, cobre e zinco (KONTOPOULOS, 1998; SILVAS et al., 2011)

A indústria da mineração produz significativas quantidades de efluentes líquidos como contrapartida de seus processos, cujas concentrações de compostos inorgânicos e metais, entre outros componentes, estão bem acima dos padrões máximos de lançamento estabelecido pela legislação (WOLOSZYN; VOLKART; BIZANI, 2013).

A DAM, um dos principais problemas ambientais associados à mineração de carvão mineral e a outras atividades da indústria mineral que contêm sulfetos metálicos, constitui uma fonte expressiva de poluição das águas superficiais e subterrâneas, criando condições impróprias à sobrevivência de seres nesse habitat, além de limitar seu uso doméstico ou industrial (MENEZES et al., 2004; KONTOPOULOS, 1998). Além da DAM, também os efluentes líquidos provenientes do processo de beneficiamento apresentam características agressivas ao meio ambiente, com altas concentra- ções de metais pesados e a presença de partículas finas e ultrafinas de difícil remoção.

O reconhecimento dos riscos ambientais da DAM tem conduzido ao desenvolvimento de várias técnicas para minimizar o impacto dessas correntes ácidas nos ecossistemas. Os sistemas convencionais de neutralização de DAM que utilizam reagentes alcalinos $\left(\mathrm{CaO}\right.$ e $\left.\mathrm{CaCO}_{3}\right)$ são os mais empregados em áreas de mineração. Esses sistemas consistem no aumento do $\mathrm{pH}$ e na remoção de metais na forma de hidróxidos. A principal característica da neutralização com reagentes alcalinos é a formação de resíduos (lama) decorrentes do processo de precipitação dos sólidos. Em geral, o processo de precipitação de constituintes químicos se dá em função do pH. Entretanto, outros fatores podem contribuir nesse processo, como força iônica, temperatura, potencial de oxidação-redução (Eh), estado de oxidação dos metais, concentrações dos metais em solução e suas interações com sólidos precipitados (KALIN; FYSON; WHEELER, 2006).

O manganês tem sido considerado como um dos principais elementos contaminantes presentes na DAM de carvão mineral, de difícil remoção nos limites permitidos pela legislação ambiental ( $\mathrm{pH} 6$ a 9). Normalmente, o manganês existe em solução sob condições normais ambientais na forma do cátion $\mathrm{Mn}^{2+}$. Em DAM, prevalece $0 \mathrm{Mn}^{2+}$ que é estável até o $\mathrm{pH}$ próximo de 10 .

Alguns métodos de tratamento de efluentes são empregados nos setores minerais com a finalidade de remover metais pesados e estabelecer condições apropriadas de descarte desses efluentes conforme os parâmetros exigidos pela legislação ambiental. Tais processos de tratamento de efluentes podem ser utilizados via neutralização, floculação e sedimentação (NFS) e via flotação por ar dissolvido (FAD). 
A remoção de manganês da DAM por sistemas convencionais de neutralização, por outro lado, tem apresentado baixa eficiência em diversos estudos (HAMMARSTROM; SIBRELL; BELKIN, 2003). Em condições oxidantes, o $\mathrm{Mn}^{2+}$ deveria sofrer oxidação espontânea para manganês trivalente ou tetravalente e, em seguida, precipitar na forma de óxidos. Porém, isso requer elevada quantidade de energia, tornando lento o processo de oxidação desse metal, especialmente em $\mathrm{pH}<8$ (POTGIETER-VERMAAK et al., 2006).

No que diz respeito à legislação vigente para este estudo, a Resolução do Conselho Nacional do Meio Ambiente (CONAMA) no 430 (BRASIL, 2011), que dispõe sobre as definições e padrões de lançamento de efluentes, vem complementar e alterar a Resolução no 357, de 17 de março de 2005. Em seu artigo 3o, resolve: “Os efluentes de qualquer fonte poluidora somente poderão ser lançados diretamente nos corpos receptores após o devido tratamento e desde que obedeçam às condições, padrões e exigências dispostos nesta Resolução e em outras normas aplicáveis" (BRASIL, 2011). Portanto, todas as unidades de tratamento de efluente, de qualquer origem, somente poderão lançar diretamente suas águas no corpo receptor desde que atendam às disposições da lei. Ressalta ainda em seu artigo 16:

Os efluentes de qualquer fonte poluidora somente poderão ser lançados diretamente no corpo receptor

\begin{abstract}
desde que obedeçam as condições e padrões previstos neste artigo, resguardadas outras exigências cabíveis: I - condições de lançamento de efluentes: a) pH entre 5 e 9; II - Padrões de lançamento de efluentes: Manganês dissolvido $1 \mathrm{mg} / \mathrm{L}$; Ferro Dissolvido $15 \mathrm{mg} / \mathrm{L} \mathrm{e}$ Zinco 5 mg/L (BRASIL, 2011).
\end{abstract}

Nesse contexto, o objetivo geral deste trabalho foi o de realizar a aplicação de métodos de tratamento de efluentes provenientes da mineração de carvão mineral, com vistas à melhoria da eficiência na remoção do manganês e de outros metais pesados como alumínio, ferro e zinco, em uma estação de tratamento de efluentes (ETE) da indústria carbonífera na região sul do estado de Santa Catarina.

Dessa forma, no presente trabalho se buscou proporcionar uma melhoria da qualidade dos recursos hídricos com base no aperfeiçoamento dos processos de tratamento de efluentes e seu posterior lançamento no sistema hídrico.

Para atender a esse objetivo, realizou-se uma revisão do estado da arte dos processos de tratamento de DAM com enfoque na remoção do manganês, fez-se a caracterização do efluente gerado pela carbonífera e conduziram-se ensaios de tratabilidade para avaliar a eficiência de remoção dos metais manganês, alumínio, ferro e zinco, com vistas à adequação dos efluentes gerados aos padrões de qualidade ambiental.

\section{MATERIAIS E MÉTODOS}

Processo de tratamento de efluentes da indústria carbonífera em estudo

A ETE da indústria carbonífera objeto deste estudo compreende as seguintes unidades:

- tanque de neutralização;

- tanque de floculação;

- sedimentador;

\section{Processo de neutralização}

Neste trabalho efetuou-se um estudo de remoção do manganês e de outros metais pesados da DAM formada com os efluentes oriundos do beneficiamento de carvão mineral. O efluente descartado pela usina de beneficiamento contém sedimentos finos e ultrafinos,
- adensamento;

- desidratação (filtro-prensa);

- bacias de decantação, conforme apresenta a Tabela 1.

A ETE apresenta capacidade para a vazão máxima de $900 \mathrm{~m}^{3} \cdot \mathrm{h}^{-1}$. Além disso, segue um regime de operação de 24 horas por dia, distribuídos em três turnos.

fração derivada do processo de lavagem do carvão. Entretanto, em um primeiro estágio, a água utilizada nesse processo apresenta pH entre 6,2 e 7,5, o que lhe confere uma condição legalmente aceitável no que diz respeito ao $\mathrm{pH}$. Esse fato deve-se à presença de mine- 
rais com características alcalinas encontrados nas camadas de carvão da região catarinense, tais como finas lentes de carbonato de cálcio.

O processo de neutralização do efluente gerado é composto de silo de armazenamento de cal, balança, tanque de preparo, filtro, bombas centrífugas e bombas dosadoras equipadas com inversor de frequência. Atualmente, utiliza-se como substância alcalinizante o hidróxido de cálcio $\left(\mathrm{Ca}(\mathrm{OH})_{2}\right)$.

No tanque de preparo é formada a solução de hidróxido de cálcio, a uma concentração, pela adição de óxido de cálcio e de água com auxílio de uma balança digital acoplada ao tanque de preparo. Posteriormente a solução é bombeada até o tanque de

\section{Processo de floculação}

Durante muitos anos a empresa utilizou o processo de FAD para o tratamento da DAM (MENEZES et al., 2004).

A flotação tem várias vantagens sobre a sedimentação por gravidade, destacando-se: possibilidade de produção de água de melhor qualidade; operação em taxas de aplicação mais altas, resultando em estações de tratamento mais compactas; início de operação mais rápido; concentração de sólidos no lodo significativamente superior à produzida na sedimentação; e menor tempo de detenção em uma estação de tratamento (MENEZES et al., 2004; OLIVEIRA; OLIVEIRA, 2019).

No entanto, atualmente o processo de NFS constitui o principal processo de tratamento de efluentes da empresa objeto deste estudo, e também da maioria das neutralização, que se constitui de caixa de recebimento do efluente seguida de três calhas Parshall. Cada uma recebe a solução de hidróxido de cálcio, com vazão de $1,8 \mathrm{~m}^{3} \cdot \mathrm{h}^{-1}$, com o auxílio de bombas dosadoras. O consumo de cal para os dados citados acima ficou na média de $180 \mathrm{~kg} / \mathrm{h}$.

Os objetivos da etapa de neutralização somente serão alcançados quando o $\mathrm{pH}$ atingir a faixa de 5 a 9, conforme estabelecido na Resolução CONAMA no 430/2011. Tal aspecto tem como objetivo reduzir os teores de manganês dissolvido, tendo em vista que a precipitação do manganês sob a forma de óxido ou hidróxido ocorre em sua maior parte na faixa de $\mathrm{pH}$ entre 8,5 e 10, segundo estudos de Ferguson (1991).

empresas da região (RUBIO; TESSELE, 2002). O processo inicia-se com o preparo da solução floculante em tanque constituído de agitador acoplado, com capacidade para 4,2 $\mathrm{m}^{3}$. Inicialmente, pesa-se a quantidade de $2,5 \mathrm{~kg}$ de polímero aniônico em pó para dissolvê-la em volume de $3,5 \mathrm{~m}^{3}$ de água sob agitação constante, apresentando a concentração de 0,71 g. $\mathrm{L}^{-1}$. Essa concentração pode variar de acordo com as condições do efluente.

A solução floculante é conduzida por meio de bomba dosadora helicoidal até o tanque de floculação. 0 consumo de floculante para as condições citadas acima

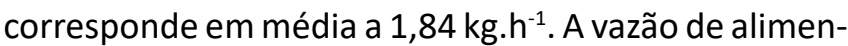
tação de efluente oriundo da etapa de neutralização nos tanques de floculação é na ordem de $250 \mathrm{~m}^{3} \cdot \mathrm{h}^{-1}$.

Tabela 1 - Descrição das unidades de tratamento da estação de tratamento de efluente (ETE).

Descrição $\quad$ Quantidade

Tanque de neutralização

Tanque de floculação

Sedimentador

Tanque de adensamento

Filtro-prensa

Bacias de decantação 
O tanque de floculação ou tanque de agitação lenta, como é comumente denominado, é anexado aos decantadores, e sua estrutura apresenta os seguintes componentes:

- entrada de alimentação;

\section{Processo de sedimentação}

O processo de sedimentação se constitui de três decantadores, com capacidade de processamento em cada linha de até $450 \mathrm{~m}^{3} \cdot \mathrm{h}^{-1}$. Na empresa, atualmente, apenas dois decantadores realizam o processo de sedimentação, enquanto o terceiro é utilizado como tanque de adensamento de lodo.

A alimentação dos decantadores inicia-se logo após a etapa de floculação. Pela ação da gravidade, as partícu-

\section{Processo de desidratação do lodo}

O processo de desidratação do lodo consiste em direcionar o material adensado (polpa) do decantador 3 até o filtro-prensa. Esse processo é composto de filtro-prensa de fabricação chinesa, automatizado, constituído de 74 placas de $2 \times 2 \mathrm{~m}$.

No local ainda se encontram duas unidades de filtro-prensa de 60 placas de $1 \times 1 \mathrm{~m}$, destinadas a desidratar a polpa proveniente da bacia de decantação do processo de flotação de partículas finas e ultrafinas provenientes do processo das instalações de beneficiamento

\section{Procedimentos experimentais}

Os procedimentos experimentais deste trabalho foram realizados em escala de bancada e compreenderam duas etapas principais. A primeira destinou-se à amostragem do efluente bruto (água preta) proveniente do processo final de beneficiamento. Esse efluente, como já mencionado, apresenta partículas finas e ultrafinas de difícil remoção e de altas concentrações de metais pesados, principalmente ferro e manganês. Na sequência, foi realizada a amostragem da água de recirculação utilizada no processo inicial do beneficiamento. Por se tratar de água de recirculação, ela apresenta algumas características semelhantes às da drenagem ácida, contendo metais dissolvidos em concentrações elevadas, o

\section{Pontos de coleta}

As amostras foram coletadas entre os meses de abril a maio de 2018. Estabeleceram-se dois pontos de coleta,
- agitador;

- bomba dosadora helicoidal;

- alimentação do decantador.

las de maior densidade sedimentam e direcionam-se para o fundo do equipamento. $\mathrm{O}$ efluente clarificado sai continuamente como overflow, passando por uma calha Parshall, tendo como destino final a bacia de estabilização. O lodo é extraído do fundo dos decantadores 1 e 2 por bombas centrífugas equipadas com inversores de frequência, e direcionado para o tanque de adensamento de lodo.

de carvão. Cada filtro-prensa tem capacidade para filtrar $37,5 \mathrm{~m}^{3}$ de lodo por ciclo. $O$ tempo estimado para cada ciclo é de $50 \mathrm{~min}$, compreendendo as etapas de filtração, sopramento e descarregamento das tortas.

O lodo desidratado, com mais de $20 \%$ de sólidos, é depositado em um compartimento existente abaixo dos filtros-prensas, sendo carregado por pá carregadeira em caminhões e transportado continuamente para o depósito de rejeitos.

que justifica a sua avaliação detalhada para este trabaIho com ênfase no manganês. Por fim, procedeu-se à caracterização físico-química dessas soluções líquidas, com a finalidade de identificar a concentração de manganês e dos demais metais pesados dissolvidos.

A segunda etapa dos procedimentos experimentais consistiu na aplicação dos métodos de tratamento de efluentes de mineração por meio dos processos de NFS e FAD, com a caracterização físico-química do sobrenadante clarificado e, posteriormente, a determinação de eficiência de remoção de manganês e dos outros metais presentes nas soluções líquidas.

denominados de pontos $A$ e $B$, localizados no perímetro da ETE da indústria carbonífera. 
O primeiro ponto $(A)$ destinou-se à coleta do efluente bruto (água preta). Esse ponto localizou-se antes da etapa de neutralização, tendo como referência a caixa de visita situada próximo à tubulação que direciona o efluente bruto proveniente da usina de beneficiamento até a ETE.

O segundo ponto (B) destinou-se à coleta da água de recirculação. Esse ponto localizou-se na bacia de cla-

\section{Procedimentos de coletas de amostras}

As coletas de efluentes foram realizadas conforme critérios estabelecidos pela Associação Brasileira de Normas Técnicas (ABNT) (NBR 9898/1987), que institui os parâmetros de preservação e técnicas de amostragem de efluentes líquidos e corpos receptores.

Diante desses parâmetros, as amostras foram coletadas manualmente e acondicionadas em recipientes de

\section{Análises físico-químicas dos efluentes}

Os ensaios físico-químicos para análise dos efluentes brutos foram realizados pelo Laboratório de Análises Químicas e Ambientais (LAQUA) da Associação Beneficente da Indústria Carbonífera de Santa Catarina (SATC).

\section{Ensaios de bancada}

Os ensaios de tratamento dos efluentes ácidos foram conduzidos no Laboratório de Química da Universidade do Extremo Sul Catarinense (UNESC). Para a realização do ensaio de NFS, utilizou-se o efluente do ponto (A), ou seja, aquele proveniente do descarte da usina de beneficiamento (água preta). Para o ensaio de FAD, utilizou-se o efluente do ponto (B), proveniente da bacia de clarificação.

O objetivo dos ensaios de bancada foi simular o processo de tratamento de efluentes atual da indústria carbonífera em estudo, bem como o processo de flotação por ar dissolvido anteriormente empregado pela mesma carbonífera, com o intuito de avaliar qual desses

\section{Ensaio de neutralização}

Para a realização dos ensaios de neutralização, preparou-se uma solução hidróxido de cálcio $\left(\mathrm{Ca}(\mathrm{OH})_{2}\right)$ com a concentração de $11,5 \%$, baseando-se nas con- rificação. Portanto, a bacia de clarificação recebe contribuições das bacias de decantação $A$ e $B$, assim como todo despejo proveniente do sistema de drenagem superficial. A bacia de clarificação tem como finalidade abastecer a usina de beneficiamento para o processamento da matéria-prima, no entanto algumas condições são necessárias para o abastecimento da usina de beneficiamento, entre elas baixa turbidez e ausência de sedimentos grosseiros.

polietileno com capacidade de 2 L. Após a coleta, os recipientes foram armazenados e mantidos sob refrigeração a $4^{\circ} \mathrm{C}$.

As amostras que se destinaram à análise físico-química foram acondicionadas em dois recipientes de $600 \mathrm{~mL}$, contendo uma alíquota $2 \mathrm{~mL}$ de ácido nítrico $65 \%$, para conservação.

Os principais parâmetros avaliados e suas metodologias de análise foram: alumínio total $\left(\mathrm{mg}^{\mathrm{L}} \mathrm{L}^{-1}\right)$; ferro dissolvido (mg. $\left.\mathrm{L}^{-1}\right)$; ferro total (mg. $\left.\mathrm{L}^{-1}\right)$; manganês dissolvido ( $m g . \mathrm{L}^{-1}$ ) e zinco total (mg. $\mathrm{L}^{-1}$ ), todos pelo método de espectrometria de emissão óptica com plasma (ICP-OES).

processos apresenta melhor eficiência na remoção de manganês, entretanto todos os ensaios de neutralização tiveram a elevação de $\mathrm{pH}$ acima de 9. Essa é uma recomendação prevista neste estudo, que teve entre os seus objetivos a remoção do manganês na faixa de $\mathrm{pH}$ compreendida entre 9 e 10, considerando-se a solubilidade em meio aquoso desse metal.

Os ensaios de tratabilidade foram executados utilizando-se, em cada um, o volume de $1 \mathrm{~L}$ de efluente bruto, com a finalidade de se obter maior controle sobre os procedimentos sequenciais de tratamento. As soluções de hidróxido de cálcio, floculante e de surfactante foram preparadas no Laboratório de Química da UNESC.

figurações de escala industrial. A cal utilizada na ETE apresenta as seguintes características: solubilidade em água; densidade aparente variando de 0,7 a $1 \mathrm{~g} \cdot \mathrm{cm}^{-3}$. 
Os ensaios de neutralização iniciaram-se com a retirada de uma alíquota de $1 \mathrm{~L}$ em uma proveta graduada, posteriormente transferida para um béquer de vidro e colocada sob agitação utilizando-se um agitador magnético e sem aquecimento da Fisatom, modelo 752. Em seguida,

\section{Ensaio de floculação}

Os ensaios de floculação consistiram na utilização de polímero aniônico Flonex 934 SH (SNF Floerger), solúvel em água, com densidade relativa variando de 0,6 a 0,9 g.cm ${ }^{-3}$.

$\mathrm{Na}$ etapa de floculação, a dosagem requerida da solução de floculante aniônico foi de $2 \mathrm{~mL} \cdot \mathrm{L}^{-1}$, confor-

\section{Ensaio de flotação por ar dissolvido}

Os ensaios de FAD consistiram no emprego de uma célula de flotação por ar dissolvido em escala bancada, fabricada pela empresa Aquaflot. Essa célula é equipada de vaso saturador com capacidade de $3 \mathrm{~L}$, e de válvula de segurança apresentando limite máximo de pressão de $6 \mathrm{kgf.cm}{ }^{-2}$.

A pressão de saturação utilizada no processo foi de $4,2 \mathrm{kgf.cm}{ }^{-2}$, com tempo de saturação de $30 \mathrm{~min}$. Além disso, fixou-se a taxa de reciclo de $60 \%$ com base em estudos anteriores envolvendo FAD, de Menezes e Leal Filho (2004). verificou-se o $\mathrm{pH}$ do efluente bruto com um pHmetro digital de bancada da marca Quimis Q-400 a, calibrado com solução tampão de pH 4 e 7. Posteriormente, elevou-se o pH da solução adicionando-se solução de hidróxido de cálcio, até atingir a faixa de $\mathrm{pH}$ ideal.

me estudos anteriores de Volpato, Menezes e Silva (2017). A concentração da solução floculante preparada no laboratório foi de $0,71 \%$. Para a agitação e homogeneização da solução foi adotado o gradiente de velocidade de $20 \mathrm{~s}^{-1}$, conforme parâmetros de diluição em planta industrial.

Para os ensaios, utilizaram-se as duas dosagens de surfactante oleato de sódio de 50 e $75 \mathrm{~mL} . \mathrm{L}^{-1}$. O primeiro ensaio, denominado de FAD $\mathrm{n}=1$, utilizou $75 \mathrm{~mL}$ de oleato de sódio. $O$ segundo ensaio, denominado de FAD n 2, realizou-se dosando $75 \mathrm{~mL}$ de oleato de sódio combinado com $2 \mathrm{~mL}$ da solução floculante, e o terceiro ensaio, denominado de FAD $\mathrm{n}$ o 3, empregou $50 \mathrm{~mL}$ de oleato de sódio. O tempo de flotação foi de $8 \mathrm{~min}$ para os três ensaios. A Figura 1 ilustra uma célula de flotação por ar dissolvido de escala de bancada.

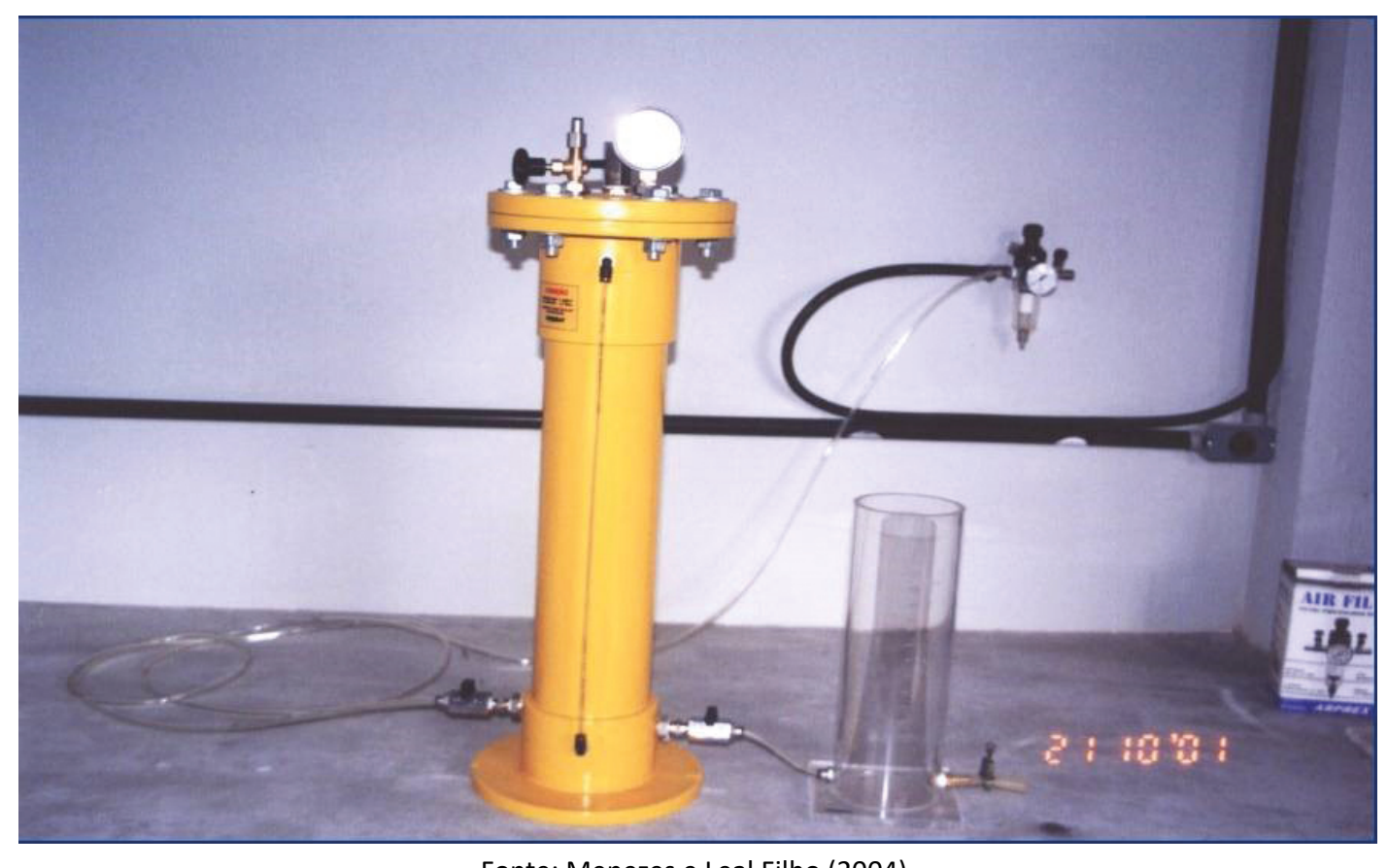

Fonte: Menezes e Leal Filho (2004).

Figura 1 - Célula de flotação por ar dissolvido de bancada. 
Ao término dos ensaios, uma alíquota da amostra foi coletada e acondicionada em recipiente contendo áci- do nítrico $65 \%$, de maneira a conservá-la. As amostras foram encaminhadas para o LAQUA.

\section{RESULTADOS E DISCUSSÃO}

\section{Resultados para o ensaio de neutralização}

O presente estudo obteve resultados que, em sua maior parte, corroboraram e aprofundaram estudos anteriores referentes ao tratamento da DAM (TRINDADE; SOARES; RIZZO, 2004; MENEZES et al., 2004), em que se afirma que a maior parte dos métodos de tratamento de DAM envolve uma etapa inicial de neutralização, tendo em vista a precipitação dos metais contidos na solução ácida. Dessa forma, alguns fatores são considerados essenciais para se obter eficiência positiva na remoção de metais pesados dos efluentes de mineração de carvão, entre os quais a escolha adequada do reagente alcalinizante, a determinação da concentração ideal e o conhecimento das faixas de precipitação dos principais hidróxidos metálicos.

A precipitação máxima do manganês como óxido ou hidróxido $\left(\mathrm{MnO}_{2}\right)$ ou $\mathrm{Mn}(\mathrm{OH})_{2}$ ocorre apenas nas faixas de $\mathrm{pH}$ de 9,5 a 10, pois, embora do $\mathrm{pH}$ de 8,6 em diante tenha início a sua precipitação, para faixas de $\mathrm{pH}$ menores que 9,5 a eficiência é insatisfatória para a remoção desse íon.

\section{Resultados para o ensaio de floculação}

A Figura 3 ilustra a variação nas características de turbidez e clarificação da solução desde a etapa de neutralização até a
Assim, os ensaios de neutralização foram realizados elevando-se o $\mathrm{pH}$ até próximo a 10 , com a perspectiva de remover a maior parte do manganês presente no efluente bruto.

Como já citado anteriormente, para o processo de NFS foi utilizado o efluente bruto (água preta) proveniente do processo de beneficiamento.

Os resultados obtidos ao longo do processo de neutralização, tanto em termos de volume utilizado quanto de variação do $\mathrm{pH}$, estão apresentados a seguir, na Tabela 2.

Para a etapa de neutralização o consumo da solução neutralizante foi de $5 \mathrm{~mL}$ para se obter o $\mathrm{pH}$ de 9,95. O resultado encontrado para esse parâmetro corroborou adequadamente as condições observadas na planta em escala industrial. Com base no ensaio de neutralização foi possível chegar à curva de neutralização, conforme ilustrado abaixo na Figura 2.

etapa de floculação, demonstrando a eficiência na formação de flocos e a precipitação dos óxidos e hidróxidos metálicos.

Tabela 2 - Ensaio 1 de neutralização com adição de solução de CaO.

\section{$\mathrm{pH}$}

inicial 7,25

8,25

8,9

9,37

9,7

9,95
$\mathrm{Ca}(\mathrm{OH})_{2}(\mathrm{~mL})$ 


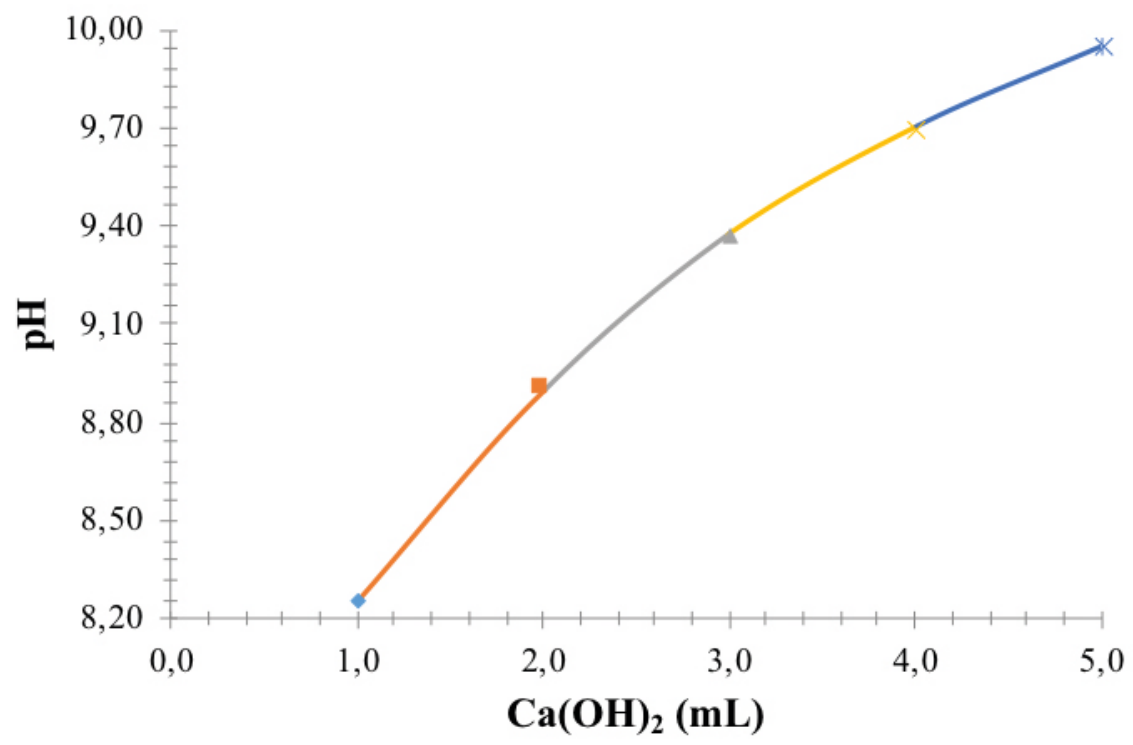

Figura 2 - Curva de neutralização com utilização de solução de $\mathrm{Ca}(\mathrm{OH})_{2}(11,5 \%)$.

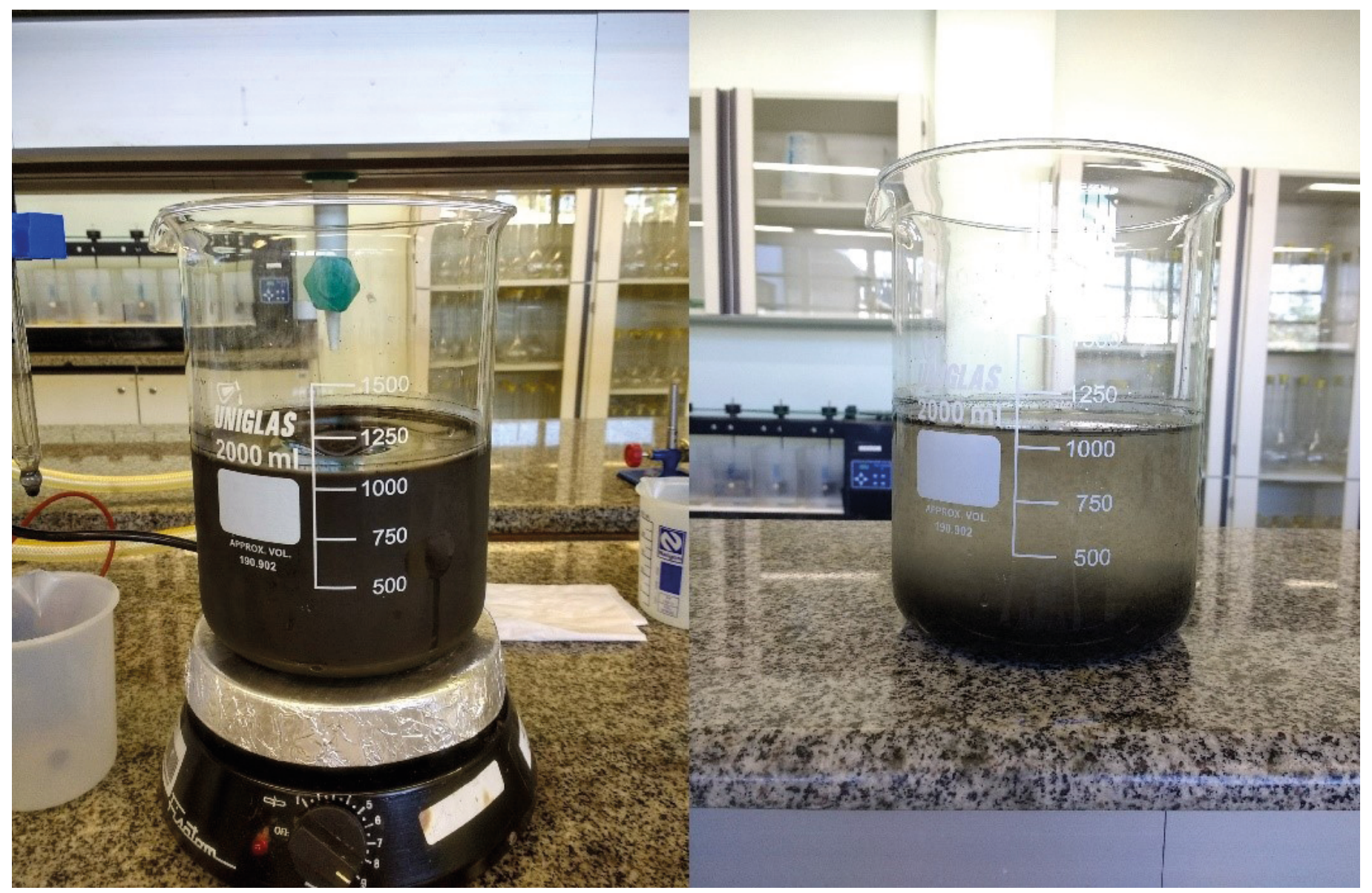

Figura 3 - Efluente bruto após o ensaio de neutralização e floculação. 


\section{Resultados integrados das análises físico-químicas após neutralização, floculação e sedimentação}

De acordo com os resultados apresentados na Tabela 3, foi possível avaliar a eficiência da remoção dos principais metais dissolvidos. Embora não tenham sido os objetos principais desta investigação, para efeito de análise da eficiência do processo de tratamento da DAM, além do manganês, foram analisadas as concentrações inicial e final e a eficiência na remoção dos elementos ferro, alumínio e zinco.

\section{Ensaio de tratamento via flotação por ar dissolvido}

A seguir são discutidos os resultados dos ensaios de tratamento pela técnica de FAD. Os ensaios foram realizados em triplicata conforme descrito na metodologia, com dosagens diferentes. Buscou-se realizar um estudo para avaliar a eficiência utilizando apenas

\section{Ensaio de flotação por ar dissolvido $n^{0} 1$}

O ensaio de FAD no 1 constituiu-se de neutralização e correção do pH da amostra, seguidas de adição do surfactante oleato de sódio $(75 \mathrm{~mL})$, com taxa de reciclo de $60 \%$. Os resultados observados ao longo do processo de neutralização, tanto em termos de volume utilizado quanto de variação do pH, são apresentados na Tabela 4.

Segundo os estudos de Campaner e Silva (2009, p. 146), "a eficiência da neutralização por reagentes
A eficiência de remoção do ferro foi de $99,79 \%$, sendo este o maior percentual de remoção entres os metais presentes no efluente ácido submetido ao tratamento utilizado. A eficiência na remoção do manganês correspondeu a 99,58\%. Dessa forma, as análises dos resultados dos ensaios de forma integrada demonstram as baixas concentrações finais obtidas para esses metais, resultando na sua adequação aos limites de lançamento estabelecidos pela legislação ambiental vigente (BRASIL, 2011).

o surfactante, o oleato de sódio, nos ensaios no 1 e no 3, e de forma combinada com o uso de um floculante no ensaio no 2. Para os dois tipos de ensaios, manteve-se uma etapa comum de neutralização e correção do $\mathrm{pH}$.

carbonáticos é fortemente influenciada por elevadas concentrações de ferro em solução". O revestimento das partículas dos reagentes por precipitados de hidróxidos de Fe pode afetar a taxa de reações químicas que consomem $\mathrm{H}^{+}$da solução. Nesse sentido, os resultados deste estudo corroboraram esses autores. A Figura 4 apresenta a projeção de uma curva de neutralização conforme os resultados encontrados.

Tabela 3 - Caracterização físico-química do efluente bruto e clarificado.

\begin{tabular}{|l|c|c|c|c|c|c|}
\hline Parâmetros & Unidade & $\begin{array}{c}\text { Resolução CONAMA } \\
\text { no 430/2011 }\end{array}$ & $\begin{array}{c}\text { Lei no } \\
14.675 / 2009\end{array}$ & $\begin{array}{c}\text { Efluente } \\
\text { bruto }\end{array}$ & $\begin{array}{c}\text { Efluente } \\
\text { clarificado }\end{array}$ & $\begin{array}{c}\text { Eficiência de } \\
\text { remoção (\%) }\end{array}$ \\
\hline Alumínio total & $\mathrm{mg} \cdot \mathrm{L}^{-1}$ & $\#$ & $\# \#$ & 118,700 & 0,170 & 99,86 \\
\hline Ferro solúvel & $\mathrm{mg} \cdot \mathrm{L}^{-1}$ & 15,0 & $\# \#$ & 52,650 & 0,113 & 99,79 \\
\hline Ferro total & $\mathrm{mg} \cdot \mathrm{L}^{-1}$ & $\#$ & $\# \#$ & 239,100 & 0,202 & 99,92 \\
\hline Manganês solúvel & $\mathrm{mg} \cdot \mathrm{L}^{-1}$ & 1,0 & 1,0 & 9,307 & 0,039 & 99,58 \\
\hline Zinco total & $\mathrm{mg} \cdot \mathrm{L}^{-1}$ & 5,0 & 1,0 & 1,468 & 0,010 & 99,32 \\
\hline pH & & 5,0 a 9,0 & 6,0 a 9,0 & 7,25 & 9,95 & $\# \#$ \\
\hline
\end{tabular}

CONAMA: Conselho Nacional do Meio Ambiente; \#valor máximo permitido (VMP) segundo o Código Estadual do Meio Ambiente de Santa Catarina - Lei no 14.675, de 13 de abril de 2009 (Padrões Ambientais dos Recursos Hídricos); \#\#Resolução no 357, de 17 de março de 2005 do CONAMA (Classe 2 - Águas Doces). 
A Tabela 5 apresenta os resultados para o ensaio de FAD no 1. Nela está ilustrada a caracterização físico-química dos efluentes bruto e clarificado. Além disso, apresenta-se a eficiência de remoção do manganês e dos demais metais pesados dissolvidos.

\section{Ensaio de flotação por ar dissolvido $n^{\circ} 2$}

O ensaio de FAD no 2 constitui-se de neutralização e correção do pH da amostra, seguidas de adição do surfactante oleato de sódio $(75 \mathrm{~mL}$ ) e da adição floculante aniônico $(2 \mathrm{~mL})$, com a taxa de reciclo de $60 \%$. Os resultados obtidos na correção de $\mathrm{pH}$ são apresentados abaixo, na Tabela 6.

A precipitação do manganês não é somente alcançada por meio do aumento de $\mathrm{pH}$, mas sofre influência também de
Os resultados da análise do efluente clarificado do ensaio FAD no 1 demonstraram eficiência satisfatória na remoção dos metais pesados analisados, com foco no manganês, objeto central deste estudo, que demonstrou eficiência de remoção de 97,84\%.

outras variáveis, como temperatura e potencial de oxirredução (SHRIVER; ATKINS; LANGFORD, 1998). Esses parâmetros não fizeram parte do escopo da presente pesquisa, mas poderão ser recomendados como objetos de estudo em futuros trabalhos. A Figura 5 apresenta a projeção de uma curva de neutralização conforme os resultados obtidos.

A Tabela 7 apresenta os resultados para o ensaio de FAD $n$ ㅇ 2. Nela estão ilustrados os resultados da carac-

Tabela 4 - Etapa de neutralização do ensaio de flotação por ar dissolvido (FAD) no 1.

pH

inicial 2,73

3,35

4,5

6,25

9,14

9,83

\section{$\mathrm{Ca}(\mathrm{OH})_{2}(\mathrm{~mL})$}

\section{1}

2

3

4

5

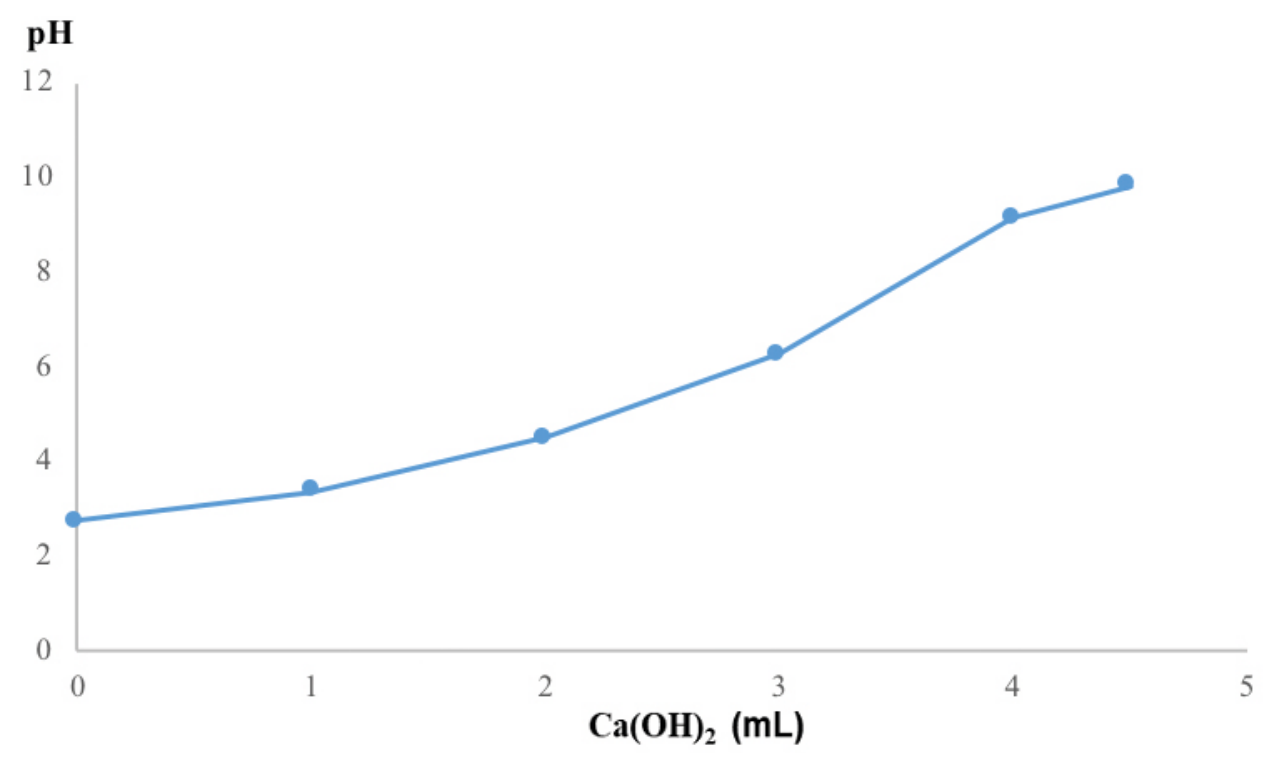

Figura 4 - Curva de neutralização do ensaio de flotação por ar dissolvido (FAD) no 1. 
Tabela 5 - Caracterização físico-química do efluente clarificado: flotação por ar dissolvido (FAD) no1.

\begin{tabular}{|c|c|c|c|c|c|c|}
\hline Parâmetros & Unidade & $\begin{array}{c}\text { Resolução CONAMA } \\
\text { n 430/2011 }\end{array}$ & $\begin{array}{c}\text { Lei } n \cong \\
14.675 / 2009\end{array}$ & $\begin{array}{l}\text { Efluente } \\
\text { bruto }\end{array}$ & $\begin{array}{l}\text { Efluente } \\
\text { clarificado }\end{array}$ & $\begin{array}{l}\text { Eficiência de } \\
\text { remoção (\%) }\end{array}$ \\
\hline Alumínio total & $\mathrm{mg} \cdot \mathrm{L}^{-1}$ & $\#$ & \#\# & 16,240 & 0,625 & 96,15 \\
\hline Ferro solúvel & $\mathrm{mg} \cdot \mathrm{L}^{-1}$ & 15,0 & \#\# & 17,240 & 0,718 & 95,84 \\
\hline Ferro total & $\mathrm{mg} \cdot \mathrm{L}^{-1}$ & \# & \#\# & 145,000 & 0,782 & 99,46 \\
\hline Manganês solúvel & $\mathrm{mg} \cdot \mathrm{L}^{-1}$ & 1,0 & 1,0 & 16,620 & 0,359 & 97,84 \\
\hline Zinco total & $\mathrm{mg} \cdot \mathrm{L}^{-1}$ & 5,0 & 1,0 & 0,950 & 0,010 & 97,79 \\
\hline $\mathrm{pH}$ & & 5,0 a 9,0 & 6,0 a 9,0 & 2,73 & 9,83 & \#\# \\
\hline
\end{tabular}

CONAMA: Conselho Nacional do Meio Ambiente; \#valor máximo permitido (VMP) segundo o Código Estadual do Meio Ambiente de Santa Catarina - Lei no 14.675, de 13 de abril de 2009 (Padrões Ambientais dos Recursos Hídricos); \#\#Resolução no 357 , de 17 de março de 2005 do CONAMA (Classe 2 - Águas Doces).

Tabela 6 - Etapa de neutralização do ensaio de flotação por ar dissolvido (FAD) no 2.

$\mathrm{pH}$

inicial 2,82

3,32

3,62

5,03

7,74

9,73

\section{$\mathrm{Ca}(\mathrm{OH})_{2}(\mathrm{~mL})$}

\section{1}

2

3

4

5

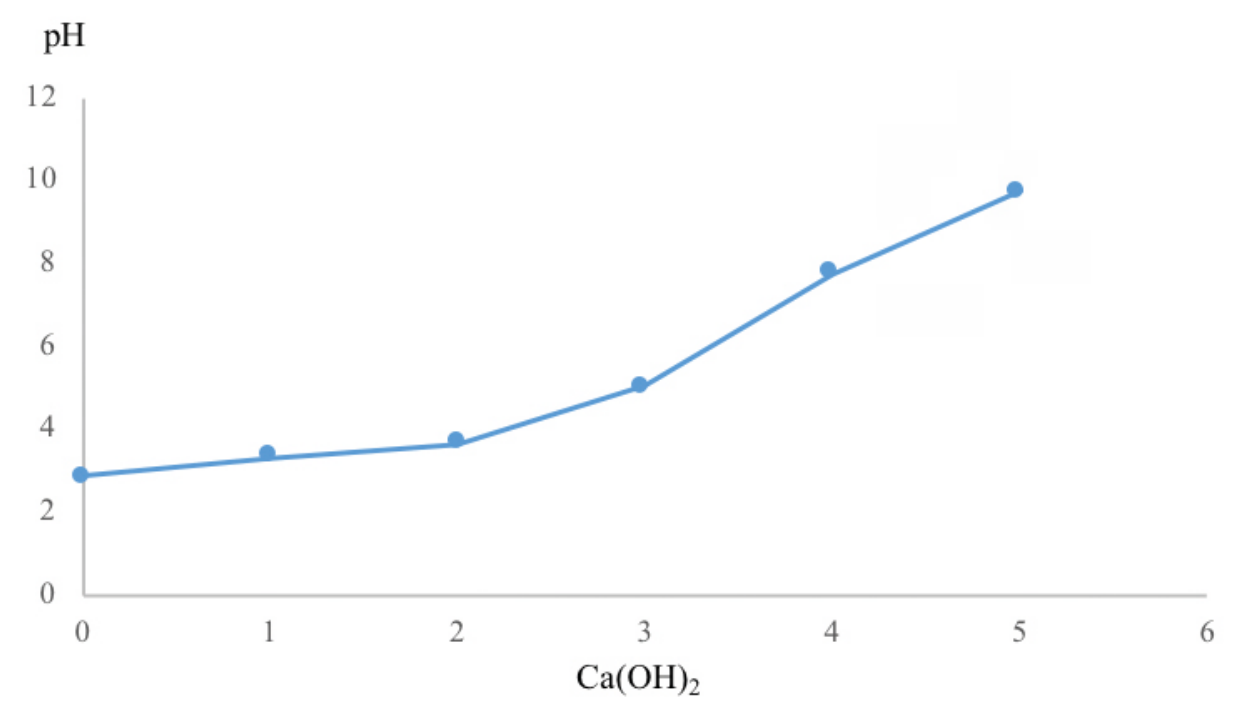

Figura 5 - Curva de neutralização do ensaio de flotação por ar dissolvido (FAD) no 2. 
terização química e físico-química do efluente bruto e clarificado. Além disso, apresenta-se a eficiência de remoção do manganês e dos demais metais presentes.

Os resultados da análise do efluente clarificado do ensaio FAD no 2 demonstraram eficiência na remoção do

\section{Ensaio de FAD $n^{\circ}-3$}

Por último, o ensaio denominado de FAD no 3 constituiu-se das etapas de neutralização e correção do $\mathrm{pH}$ da amostra, seguidas de adição do surfactante oleato de sódio $(50 \mathrm{~mL})$, com taxa de reciclo de $60 \%$. Os resultados observados na correção de $\mathrm{pH}$ são descritos na Tabela 8.

A curva de neutralização, elaborada conforme se apresente abaixo na Figura 6, ilustra a variação do pH com relação à adição de $\mathrm{Ca}(\mathrm{OH})_{2}$.

A Tabela 9 apresenta os resultados para o ensaio de FAD no 3. Nela estão demonstrados os resultados da todos os metais analisados, com enfoque ao manganês, com remoção de 95,94\%. Essa eficiência apresentou-se satisfatória, além de adequar a concentração desse metal, o manganês, aos limites de legislação ambiental vigente (BRASIL, 2011).

caracterização química e físico-química dos efluentes bruto e clarificado.

Os resultados da análise do efluente clarificado do ensaio FAD no 3 mostraram-se eficientes na remoção dos metais alumínio, ferro, manganês e zinco, com destaque ao manganês, para o qual a eficiência de remoção correspondeu a 97,59\%. Diante disso, pode-se concluir também para esse ensaio que a eficiência na remoção de manganês se apresentou satisfatória, além de enquadrar esse elemento nos limites de concentração para o lançamento de efluentes preconizados pela legislação ambiental em vigor (BRASIL, 2011).

Tabela 7 - Caracterização físico-química do efluente clarificado (FAD no 2).

\begin{tabular}{|l|c|c|c|c|c|c|}
\hline Parâmetros & Unidade & $\begin{array}{c}\text { Resolução CONAMA } \\
\text { no 430/2011 }\end{array}$ & $\begin{array}{c}\text { Lei no } \\
\mathbf{1 4 . 6 7 5 / 2 0 0 9}\end{array}$ & $\begin{array}{c}\text { Efluente } \\
\text { bruto }\end{array}$ & $\begin{array}{c}\text { Efluente } \\
\text { clarificado }\end{array}$ & $\begin{array}{c}\text { Eficiência de } \\
\text { remoção (\%) }\end{array}$ \\
\hline Alumínio total & $\mathrm{mg} \cdot \mathrm{L}^{-1}$ & $\#$ & $\# \#$ & 16,240 & 0,591 & 96,36 \\
\hline Ferro solúvel & $\mathrm{mg} \cdot \mathrm{L}^{-1}$ & 15,0 & $\# \#$ & 17,240 & 0,139 & 99,19 \\
\hline Ferro total & $\mathrm{mg} \cdot \mathrm{L}^{-1}$ & $\#$ & $\# \#$ & 145,000 & 0,157 & 99,89 \\
\hline Manganês solúvel & $\mathrm{mg} \cdot \mathrm{L}^{-1}$ & 1,0 & 1,0 & 16,620 & 0,675 & 95,94 \\
\hline Zinco total & $\mathrm{mg} \cdot \mathrm{L}^{-1}$ & 5,0 & 1,0 & 0,950 & 0,039 & 95,89 \\
\hline pH & & 5,0 a 9,0 & 6,0 a 9,0 & 2,73 & 9,73 & $\# \#$ \\
\hline
\end{tabular}

CONAMA: Conselho Nacional do Meio Ambiente; \#valor máximo permitido (VMP) segundo o Código Estadual do Meio Ambiente de Santa Catarina - Lei no 14.675, de 13 de abril de 2009 (Padrões Ambientais dos Recursos Hídricos); \#\#Resolução no 357 , de 17 de março de 2005 do CONAMA (Classe 2 - Águas Doces).

Tabela 8 - Etapa de neutralização do ensaio de flotação por ar dissolvido (FAD) no 3.

\section{pH}

inicial 2,98

3,37

4,7

6,4

9,4

\section{$\mathrm{Ca}(\mathrm{OH})_{2}(\mathrm{~mL})$}

1

2

3

4 


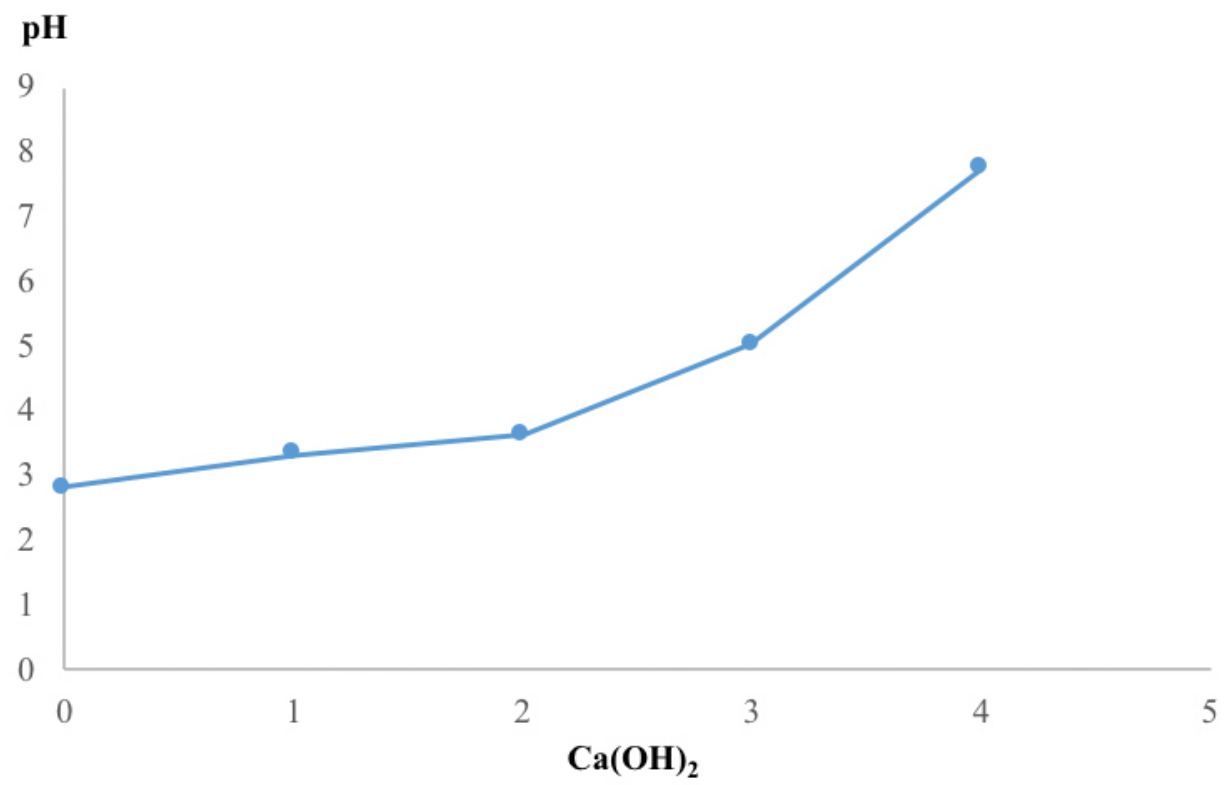

Figura 6 - Curva de neutralização do ensaio de flotação por ar dissolvido (FAD) no 3.

Tabela 9 - Caracterização físico-química do efluente clarificado: flotação por ar dissolvido (FAD) no 3.

\begin{tabular}{|l|c|c|c|c|c|c|}
\hline Parâmetros & Unidade & $\begin{array}{c}\text { Resolução CONAMA } \\
\text { no 430/2011 }\end{array}$ & $\begin{array}{c}\text { Lei no } \\
\mathbf{1 4 . 6 7 5 / 2 0 0 9}\end{array}$ & $\begin{array}{c}\text { Efluente } \\
\text { bruto }\end{array}$ & $\begin{array}{c}\text { Efluente } \\
\text { clarificado }\end{array}$ & $\begin{array}{c}\text { Eficiência de } \\
\text { remoção (\%) }\end{array}$ \\
\hline Alumínio total & $\mathrm{mg} \cdot \mathrm{L}^{-1}$ & $\#$ & $\#$ & 16,24 & 0,569 & 96,50 \\
\hline Ferro solúvel & $\mathrm{mg} \cdot \mathrm{L}^{-1}$ & 15,0 & $\#$ & 17,24 & 0,559 & 96,76 \\
\hline Ferro total & $\mathrm{mg} \cdot \mathrm{L}^{-1}$ & $\#$ & $\#$ & 145 & 0,615 & 99,58 \\
\hline Manganês solúvel & $\mathrm{mg} \cdot \mathrm{L}^{-1}$ & 1,0 & 1,0 & 16,62 & 0,401 & 97,59 \\
\hline Zinco total & $\mathrm{mg} \cdot \mathrm{L}^{-1}$ & 5,0 & 1,0 & 0,95 & 0,025 & 97,37 \\
\hline pH & & 5,0 a 9,0 & 6,0 a 9,0 & 2,98 & 9,83 & \\
\hline
\end{tabular}

CONAMA: Conselho Nacional do Meio Ambiente; \#valor máximo permitido (VMP) segundo o Código Estadual do Meio Ambiente de Santa Catarina - Lei no 14.675, de 13 de abril de 2009 (Padrões Ambientais dos Recursos Hídricos); \#\#Resolução no 357, de 17 de março de 2005 do CONAMA (Classe 2 - Águas Doces).

\section{CONCLUSÃO}

Com base nos resultados experimentais obtidos no âmbito deste trabalho foi possível concluir que tanto a DAM quanto a água de processo, denominada localmente na indústria carbonífera de água preta e oriunda da etapa de beneficiamento, apresentam diferenças significativas em termos de valores de $\mathrm{pH}$ e altas concentrações de metais pesados, muitas delas acima dos limites permitidos pela legislação ambiental vigente, tais como as de ferro, zinco e manganês. Enquanto a DAM apresenta valores de $\mathrm{pH}$ compreendidos entre 2,7 e 3 , a água proveniente do processo de beneficiamento apresenta valores de $\mathrm{pH}$ entre 6 e 7,5.
O ensaio por meio das etapas de NFS apresentou eficiência de 99,6\% na remoção do manganês dissolvido nas amostras de efluente bruto e $99,8 \%$ na remoção do ferro, entretanto a obtenção dessa eficiência associada ao tratamento físico-químico somente foi possível com a elevação de $\mathrm{pH}$ para acima de 9 . Assim, esse parâmetro deverá ser objeto de pesquisas futuras, visando à sua adequação de forma integral à legislação ambiental. Resta a necessidade da adequação do manganês a valores de $\mathrm{pH}$ abaixo de 9 . No entanto, com relação aos demais parâmetros, os ensaios de NFS corroboraram os dados obtidos por Volpato, Menezes e Silva (2017), 
com semelhante eficiência na remoção dos íons metais ferro e manganês.

Para os ensaios em triplicata por meio da FAD, a eficiência de remoção de manganês apresentou algumas variações. Para o ensaio no 1 , a eficiência de remoção foi de $97,84 \%$, com o pH compreendido na faixa de 9,83 . No ensaio de no 2, obteve-se menor eficiência na remoção de manganês, na faixa de 95,94\%, mesmo associado com o floculante. Para o ensaio de no 3 , a eficiência na remoção do manganês correspondeu ao valor médio de $97,59 \%$. Nesse ensaio o $\mathrm{pH}$ foi elevado até 9,4 e foram usados $50 \mathrm{~mL}$ de oleato de sódio. Para tais ensaios fixou-se a taxa de reciclo de $60 \%$.

Apesar de algumas variações na remoção de manganês nas amostras de efluentes, todos os ensaios se enquadraram nos limites estabelecidos pela legislação ambiental. Isso comprova que o processo de tratamento de efluente comumente utilizado na carbonífera em estudo apresenta eficiência para a remoção dos metais pesados analisados, sobretudo ferro, zinco e manganês.

Sobre a aplicação do processo de FAD, pode-se concluir que ele se apresenta como alternativa concreta, corroborando trabalhos anteriores (MENEZES et al., 2004). Embora pouco utilizado nas carboníferas da região atualmente, apresenta eficiência tanto técnica como ambiental, e todos os parâmetros analisados foram contemplados pela legislação vigente, o que justifica uma possível reintrodução futura nos sistemas de tratamento da DAM na região.
Ressalta-se que essa técnica se mostrou promissora e é possível que seja uma boa alternativa à recirculação de água no próprio sistema e ao lançamento em curso de água, entretanto estudos mais aprofundados devem ser conduzidos, principalmente no que diz respeito à segurança sanitária da água.

Com os resultados alcançados, vale salientar que tratamentos da DAM apenas com aplicação da etapa de neutralização não são suficientes para a remoção total dos metais tóxicos presentes nesse tipo de efluente, por duas razões principais: uma, a ampla faixa de variação de solubilidade e precipitação dos metais, por causa da formação de óxidos e hidróxidos metálicos sob forma de partículas e agregados coloidais, que constituem um lodo de difícil remoção. Além desse aspecto, os custos de separação do lodo gerado pelos óxidos e hidróxidos metálicos, via de regra, são muito elevados nos processos convencionais de separação solido-líquido, tais como filtros-prensas, necessitando de tratamentos posteriores químicos e/ou físico-químicos para uma eficiência maior da sua remoção do meio aquoso.

Como sugestão para trabalhos futuros em continuidade a este, sugere-se, para o tratamento de efluentes ácidos de mina, a inclusão de ensaios ecotoxicológicos, visando à segurança sanitária da água. Recomendam-se, ainda, estudos visando à remoção de partículas finas e ultrafinas presentes nos efluentes oriundos do beneficiamento de carvão mineral.

\section{AGRADECIMENTO}

Apresentamos os agradecimentos à empresa carbonífera e aos profissionais envolvidos no desenvolvimento da pesquisa, bem como à UNESC, onde foram desenvolvidos os ensaios de tratamento em escala de laboratório, e ao Programa de Suporte à Pós-Graduação de Instituições Comunitárias de Ensino Superior da Coordenação de Aperfeiçoamento de Pessoal de Nível Superior (PROSUC/CAPES), a bolsa de uma das autoras

\section{REFERÊNCIAS}

ASSOCIAÇÃO BRASILEIRA DE NORMAS TÉCNICAS. NBR 9898: Preservação e técnicas de amostragem de afluente líquidos e corpos receptores - Procedimento. Rio de Janeiro: ABNT, 1987.

CAMPANER, V.P.; SILVA, W.L. Processos físico-químicos em drenagem ácida de mina em mineração de carvão no sul do Brasil. Química Nova, São Paulo, v. 32, n. 1, p. 146-152, 2009. https://doi.org/10.1590/S0100-40422009000100028

CONAMA. Resolução $n^{\circ}$ 430, de 13 de maio de 2011. MMA, 2011. Disponível em: <http://www2.mma.gov.br/port/ conama/legiabre.cfm?codlegi=646>. Acesso em: 25 jun. 2020. 
FERGUSON, J.E. The heavy elements: chemistry, environmental impact and health effects. Oxford: Pergamon Press, 1991. $190 \mathrm{p}$.

HAMMARSTROM, J.M.; SIBRELL, P.L.; BELKIN, H.E. Characterization of limestone reacted with acid-mine drainage in a pulsed limestone bed treatment system at the Friendship Hill National Historical Site, Pennsylvania, USA. Applied Geochemistry, v. 18, p. 1705-1721, 2003. https://doi.org/10.1016/S0883-2927(03)00105-7

KALIN, M.; FYSON, A.; WHEELER, W.N. The chemistry of conventional and alternative treatment systems for the neutralization of acid mine drainage. Science of the Total Environment, v. 366, n. 2-3, p. 395-408, 2006. https://doi. org/10.1016/j.scitotenv.2005.11.015

KONTOPOULOS, A. Acid Mine Drainage Control. In: CASTRO, S.H.; VERGARA, F.; SÁNCHEZ, M.A. (orgs.). Efluent Treatment in the Mining Industry. Chile: University of Concepción, 1998. p. 57-118.

MENEZES, C.T.B.; LEAL FILHO, L.S. Tratamento de efluentes ácidos de mina por neutralização e remoção de metais. Boletim Técnico da Escola Politécnica da USP / Departamento de Engenharia de Minas e Petróleo, São Paulo, n. 212, p. 1-20, mar. 2004.

MENEZES, C.T.B.; LEAL FILHO, L.S.; SANTO, E.L; RUBIO, J.; ROSA, J.J.; GALATTO, S.L.; IZIDORO, G. Tratamento de Drenagem Ácida de Mina: Experiência da Carbonífera Metropolitana. IN: ENCONTRO NACIONAL DE TRATAMENTO DE MINÉRIOS E METALURGIA EXTRATIVA, 20., 2004. Anais... Florianópolis, 2004.

MENEZES, C.T.B.; TABOADA, A.E.; CHAVES, A.P. Flotação do carvão no Brasil. In: CHAVES, A.P. (org.). Flotação: o estado da arte no Brasil. São Paulo: Signus, 2006. v. 4. p. 369-379. (Coleção Teoria e Prática do Tratamento de Minérios).

OLIVEIRA, A.L.; OLIVEIRA, N.F. Flotação por ar dissolvido aplicada no tratamento de efluente de leitos de drenagem. Revista DAE, n. 218, v. 67, 2019. https://doi.org/10.4322/dae.2019.032

POTGIETER-VERMAAK, S.S.; POTGIETER, J.H.; MONAMA, P.; VAN GRIEKEN, R. Comparison of limestone, dolomite and fly ash as pre-treatment agents for acid mine drainage. Minerals Engineering, v. 19, n. 5, p. 454-462, 2006. https://doi. org/10.1016/j.mineng.2005.07.009

RUBIO, J.; TESSELE, F. Processos para o Tratamento de Efluentes da Mineração. In: BENVINDO, A.L.; SAMPAIO, J.A.; ALMEIDA, S.L.M. (orgs.). Tratamento de Minérios. 3. ed. Rio de Janeiro: CETEM/MCT, 2002. p. 637-697.

SHRIVER, D.F.; ATKINS, P.W.; LANGFORD, C.H. Inorganic chemistry. 6. ed. Oxford: Oxford University Press, 1998. 819 p. SILVAS, F.P.C.; BUZZI, D.C.; BERNARDES, A.M.; ESPINOA, D.C.R.; TENÓRIO, J.A.S. Caracterização e neutralização de drenagens ácidas de minas provenientes da mineração de carvão em Santa Catarina. Revista Brasileira de Ciências Ambientais, n. 20, 2011.

TRINDADE, R.B.E.; SOARES, P.S.M.; RIZZO, A.C.L. Remoção de manganês residual contido em efluentes aquosos de mineração. In: ENCONTRO NACIONAL DE TRATAMENTO DE MINÉRIOS E METALURGIA EXTRATIVA, 20., 2004. Anais... Florianópolis, 2004.

VOLPATO, S.B.; MENEZES, C.T.B.; SILVA, J.V.F. Recuperação ambiental de ecossistemas aquáticos em regiões estuarinas: estudos aplicados para o tratamento de sedimentos contaminados pela drenagem ácida de mina na Bacia Hidrográfica do Rio Urussanga, Santa Catarina. Engenharia Sanitária e Ambiental, v. 22, n. 2, p. 313-316, 2017. https://doi. org/10.1590/s1413-41522016126487

WOLOSZYN, D.; VOLKART, P.A.; BIZANI, D. Tratamento de efluente secundário proveniente do beneficiamento do carvão mineral utilizando bactérias com capacidade redutora de sulfato. Revista Brasileira de Ciências Ambientais, n. 28 , 2013. 